\title{
ESTIMATIVA DO NÍVEL DE DANO ECONÔMICO DE MAHANARVA FIMBRIOLATA (STÅL) (HEMIPTERA: CERCOPIDAE) EM CANA-DE-AÇÚCAR $\left(^{1}\right)$
}

\author{
LEILA LUCI DINARDO-MIRANDA $\left({ }^{*}\right)$; MARCELO ALEX GIL $\left({ }^{2}\right)$
}

\begin{abstract}
RESUMO
O nível de dano econômico de Mahanarva fimbriolata (Stål) em cana-de-açúcar foi estimado em experimento em campo, em área colhida em fim de safra (novembro), aplicando-se thiamethoxam nas doses de 150, 200 e 250 g i.a.ha ${ }^{-1}$, quando as populações da praga eram de 1,8 (4/12/02), 7,6 (17/12/02) ou 12,4 cigarrinhas.m ${ }^{-1}(26 /$ 12/02). Parcelas testemunhas sem inseticida foram mantidas. Após as aplicações, as infestações de cigarrinha foram estimadas mensalmente e em 26/9/03 o experimento foi colhido. O controle de cigarrinha pela aplicação de inseticida resultou em incremento de produtividade de colmos e de açúcar, em relação à testemunha. Aplicações feitas sob infestações de $1,8(04 / 12 / 02)$ ou 7,6 (17/12/02) resultaram em maior produtividade do que aplicações feitas com populações de 12,4 cigarrinhas. $\mathrm{m}^{-1}$. Na média, as três doses de thiamethoxam tiveram comportamento semelhante, mas houve interação entre dose e época ou infestação por ocasião das aplicações. Quando as aplicações foram feitas em 4/12/02, sob infestação de 1,8 cigarrinhas. $\mathrm{m}^{-1}$, o tratamento com thiamethoxam a $250 \mathrm{~g}$ i.a.ha ${ }^{-1}$ resultou em produtividade de colmos e de açúcar total recuperável superior à do tratamento com 150 g i.a.ha ${ }^{-1}$, fato atribuído ao maior residual e melhor controle inicial da praga, proporcionado pela dose maior. Pela análise econômica observou-se que thiamethoxam a $250 \mathrm{~g}$ i.a.ha- ${ }^{-1}$ aplicado com infestação de 1,8 cigarrinhas. $\mathrm{m}^{-1}$ proporcionou o maior lucro, e enquanto aplicado na dose de $250 \mathrm{~g}$ i.a.ha ${ }^{-1}$, sob infestação de 12,4 cigarrinhas. $\mathrm{m}^{-1}$, a menor receita líquida. Análises de regressão permitiram estimar o nível de dano econômico da praga, nas condições do presente experimento, entre 3 e 5 cigarrinhas. ${ }^{-1}$.
\end{abstract}

Palavras-chave: Insecta, cigarrinha-das-raízes, Saccharum.

\section{ABSTRACT \\ ASSESSMENT OF THE ECONOMIC INJURY LEVEL OF MAHANARVA FIMBRIOLATA (STÅL) (HEMIPTERA: CERCOPIDAE) TO SUGARCANE}

\begin{abstract}
The economic injury level of Mahanarva fimbriolata (Stål) to sugarcane was experimentally evaluated in a field area harvested at November. The inseticide thiamethoxam was applied: 150, $200 \mathrm{e} 250 \mathrm{~g}$ i.a.h ${ }^{-1}$. Applications started when the pest populations reached of 1.8 spittlebugs.m ${ }^{-1}(12 / 04 / 02), 7.6$ spittlebugs.m ${ }^{-1}(12 / 17 / 02)$ or 12.4 spittlebugs. $\mathrm{m}^{-1}(12 / 26 / 02)$. Untreated plots were maintained as check. After the insecticide applications, infestations of the sugarcane root froghopper were monthly evaluated till 9/26/03 when the experiment was harvested. Compared with check plots, the pest control resulted in significant increment of sugar productivity. When applied under infestation of $1.8(12 / 04 / 02)$ or $7.6(12 / 17 / 02)$ the productivity was resulted higher than control made with populations of 12,4 spittlebugs.m ${ }^{-1}$. Thiamethoxam was efficient when applied in all of the three doses. It was observed interaction between dose and time of insecticide application. When the applications had been made in $12 / 04 / 02$, under infestation of 1,8 spittlebugs. ${ }^{-1}$, the treatment with thiamethoxam $250 \mathrm{~g}$ i.a.ha ${ }^{-1}$ resulted in stalks and sugar productivities higher than the treatment with $150 \mathrm{~g}$ i.a.ha ${ }^{-1}$. This fact was attributed to the greater amount of residue and better initial control of the pest, obtained with the highest dose. The economic analysis of the data showed that thiamethoxam at $250 \mathrm{~g}$ i.a.ha ${ }^{-1}$ applied with the infestation of 1.8 spittlebugs. $\mathrm{m}^{-1}$, provided the greatest profit, whereas when applied at the dose of $250 \mathrm{~g}$ i.a.ha ${ }^{-1}$, under infestation of 12.4 spittlebugs. ${ }^{-1}$, the smallest net income was obtained. Regression analysis allowed the estimation of the economic injury level for the pest, in the present experimental conditions, as ranging from 3 to 5 spittlebugs. ${ }^{-1}$.
\end{abstract}

Key words: Insecta, sugarcane root froghopper, Saccharum.

( $\left.{ }^{1}\right)$ Recebido para publicação em 14 de junho de 2005 e aceito em 15 de agosto de 2006.

$\left({ }^{2}\right)$ Instituto Agronômico, Centro Avançado de Pesquisa Tecnológica de Cana-de-Açúcar, Caixa Postal 206, 14001-970 Ribeirão Preto (SP). E-mail: leiladinardo@iac.sp.gov.br* Autora correspondente. 


\section{INTRODUÇÃO}

A magnitude dos danos causados pela cigarrinha-das-raízes, Mahanarva fimbriolata (Stål) (Hemiptera: Cercopidae) à cana-de-açúcar pode ser demonstrada com clareza em campos experimentais infestados, tal como em DinARDo-Miranda et al. (2004), no qual a aplicação de inseticidas resultou em incrementos de produtividade da variedade RB835089 de até $14 \mathrm{t} \mathrm{ha}^{-1}$, ou $18 \%$, em decorrência de redução populacional da praga. Exemplo mais contundente foi relatado por DinARDo-Miranda et al. (2001b), envolvendo a variedade SP71-3250, que, atacada pela cigarrinha-das-raízes, produziu $32 \%$ mais quando tratada com inseticida, em relação às parcelas sem tratamento (testemunhas). Também MACEDO et al (2003) relataram incrementos de produtividade de colmos de até $40 \mathrm{t} \mathrm{ha} \mathrm{a}^{-1}$ na variedade SP80-1842, em decorrência do controle químico da cigarrinha-das-raízes.

Além de reduzir a produtividade de colmos, a cigarrinha-das-raízes altera a qualidade tecnológica da cana-de-açúcar, utilizada como matéria-prima na indústria, reduzindo o teor de açúcar nos colmos e aumentando o de fibra (DinARDo-Miranda et al., 2000; GONÇALVES et al., 2003). No entanto, para uma medida mais precisa dos danos causados pela cigarrinha, é necessário adicionar às reduções na produtividade de colmos e de açúcar os prejuízos nos processos industriais. Os colmos mortos e secos, em decorrência do ataque da praga, diminuem a capacidade de moagem e, como muitas vezes, estão rachados e deteriorados, os contaminantes dificultam a recuperação de açúcar e inibem a fermentação, reduzindo, portanto, os rendimentos industriais e dificultando a obtenção de açúcar de qualidade (Dinardo-Miranda, 2003).

Dada a importância da praga, muito se discute sobre quando se deve adotar medidas de controle, ou químicas ou biológicas, o que implica a determinação do nível de dano econômico. Assim, o objetivo do presente trabalho foi avaliar o efeito do controle químico da cigarrinha, feito sob diferentes infestações, sobre a produtividade da cana-de-açúcar e os rendimentos econômicos do canavial, visando estimar o nível de dano econômico da praga.

\section{MATERIAL E MÉTODOS}

O experimento foi desenvolvido na Usina Iracema, em Iracemápolis (SP), em área cultivada com a variedade RB855536, cujo segundo corte havia sido efetuado em novembro de 2002. Para o desenvolvimento do ensaio, selecionou-se área homogênea em relação à brotação da soqueira e com número reduzido de falhas. As parcelas foram representadas por cinco sulcos de $10 \mathrm{~m}$, espaçados entre si por 1,40 m, em delineamento de blocos ao acaso com seis repetições.

Após a demarcação das parcelas, realizaramse avaliações periódicas de infestações de cigarrinha, de maneira que as aplicações de thiamethoxam nas doses de 150, 200 e 250 g i.a. ha ${ }^{-1}$, utilizadas comercialmente, fossem realizadas quando as populações estivessem ao redor de 1,5 e 10 cigarrinhas $\mathrm{m}^{-1}$. Dessa forma, as aplicações foram feitas em $4 / 12 / 02,17 / 12 / 02$, e $26 / 12 / 02$, quando as infestações na área estavam em 1,8, 7,6 e 12,4 cigarrinhas $\mathrm{m}^{-1}$ respectivamente. Parcelas-testemunha (sem inseticida) foram mantidas, resultando em um ensaio em esquema fatorial $3 \times 3$, no qual um dos fatores correspondeu às três doses de thiamethoxam e o outro às três infestações por ocasião das aplicações de inseticidas, mais um tratamento adicional (testemunha). O inseticida foi aplicado com equipamento costal pressurizado, com jato dirigido para a base dos colmos.

Após as aplicações, as infestações da praga foram estimadas mensalmente. Em todas as amostragens, avaliaram-se $2 \mathrm{~m}$ de sulco em cada parcela, onde se contaram ninfas e eventuais adultos nas raízes, assim como em DinARDo-Miranda et al (1999, 2000, 2001a, 2001b, 2003 e 2004). Para visualizar os insetos nas raízes, a palha foi cuidadosamente afastada da linha de cana e os insetos foram retirados da região radicular, na subsuperfície do solo, com auxílio de um palito de madeira, com cerca de $20 \mathrm{~cm}$ de comprimento e 0,5 cm de diâmetro.

Na colheita, feita em 26/9/03, obtiveram-se as produtividades de colmos, pelo corte e pesagem dos colmos de todos os sulcos de cada parcela. Na mesma ocasião e imediatamente antes do corte, retirou-se uma amostra por parcela, composta por dez colmos coletados consecutivamente no sulco central, para análise dos parâmetros tecnológicos, de acordo com a sistemática de pagamento de cana pelo teor de sacarose (PCTS). Dessa forma, obtiveram-se, entre outros parâmetros, os valores de pol (porcentagem aparente de sacarose contida na cana) e fibra (porcentagem de matéria insolúvel em água contida no caldo), utilizados na estimativa do ATR (açúcar total recuperável, expresso em $\mathrm{kg} \mathrm{t}^{-1}$ de cana), como definido em FERNANDEZ (2003).

Para análise estatística, os dados de infestação de cigarrinha foram transformados em raiz quadrada de $(x+0,5)$ e todas as médias, comparadas pelo teste de Tukey. 
A viabilidade econômica dos tratamentos foi estimada considerando a margem de contribuição agroindustrial (MCAI), que representa a diferença entre a receita esperada com os produtos (açúcar e álcool) e os gastos nas áreas agrícola (arrendamento, corte, carregamento e transporte, tratos culturais) e industrial (processamento da matéria-prima) (Fernandez, 2003). Para o cálculo da MCAI, utilizouse planilha constante em Fernandez (2003), adotando-se os preços ocorrentes em dezembro de 2004 (ATR: R\$ 0,2344 por kg; açúcar: R \$ 0,3227 por kg; álcool: R\$ 0,92732 por litro; custo de corte, carregamento e transporte da matéria-prima: $\mathrm{R} \$ 12,00$ por tonelada de cana; custo dos processos industriais: $\mathrm{R} \$ 12,50$ por tonelada de cana; custo da aplicação de thiamethoxam a 150, 200 e 250 g i.a. ha ${ }^{-1}$ : R \$ 192,00 por ha, R\$ 246,00 por ha ou $R \$ 300,00$ por ha respectivamente). Admitiram-se ainda a eficiência industrial de $88 \%$, rendimento de pol para açúcar de $60 \%$ e rendimento da destilaria de $0,5788 \mathrm{~L} \cdot \mathrm{kg}^{-1}$ de ATR, como em FERNANDEZ (2003).

Para a estimativa do nível de dano econômico da cigarrinha-das-raízes foram elaboradas curvas de regressão entre as infestações por ocasião das aplicações e as MCAIs resultantes, considerando como MCAI de plantas não infestadas (MCAI esperada na ausência da praga) o valor estimado pelas curvas de regressão.

\section{RESULTADOS E DISCUSSÃO}

A infestação média de $M$. fimbriolata, na área experimental, por ocasião da instalação do experimento $(4 / 12 / 02)$ estava em 1,8 cigarrinhas $\mathrm{m}^{-}$ 1 , razão pela qual foi considerada a infestação quando da primeira aplicação do inseticida. Da mesma forma, 7,6 e 12,4 cigarrinhas $\mathrm{m}^{-1}$ foram consideradas as infestações médias por ocasião da segunda $(17 / 12$ / 02 ) e da terceira aplicação $(26 / 12 / 02)$ do inseticida, respectivamente, por representarem as médias das parcelas não tratadas com inseticidas, até então.

Com os dados observados em $17 / 12 / 02$, treze dias após a primeira aplicação de inseticidas, procedeu-se à análise do experimento como se ele estivesse em delineamento em blocos ao acaso, pois somente os tratamentos referentes à primeira aplicação $(4 / 12 / 02)$ haviam sido aplicados, razão pela qual os parâmetros estatísticos não foram apresentados na Tabela 1. Nessa ocasião, parcelas que receberam 150 ou $200 \mathrm{~g}$ i.a. ha ${ }^{-1}$ de thiamethoxam tiveram, respectivamente, infestação de 5,7 e 4,8 cigarrinhas. $\mathrm{m}^{-1}$ não diferindo da testemunha $(7,6$ cigarrinhas. $\mathrm{m}^{-1}$ ) ou do tratamento com $250 \mathrm{~g}$ i.a. ha ${ }^{-1}$ de thiamethoxam $\left(2,7\right.$ cigarrinhas. $\left.\mathrm{m}^{-1}\right)$. Com esse tratamento, no entanto, ocorreu infestação inferior à da testemunha, revelando que thiamethoxam a 250 g i.a. ha ${ }^{-1}$ foi mais efetivo em reduzir as populações da praga.

Diferenças entre as três doses de thiamethoxam quanto às infestações de cigarrinha não foram observadas também nas demais amostragens (Tabela 1).

Influência da infestação por ocasião das aplicações de inseticida (infestação inicial) sobre as infestações posteriores da praga foi observada somente na amostragem de 26/1/03, quando em parcelas tratadas sob infestação inicial de 1,8 cigarrinhas $\mathrm{m}^{-1}(4 / 12 / 02)$ ocorreu menor infestação do que nas parcelas tratadas mais tardiamente, quando as infestações estavam em 7,6 (17/12/02) e 12,4 cigarrinhas $\mathrm{m}^{-1}(26 / 12 / 02$, Tabela 1$)$.

Não houve interação entre infestação por ocasião das aplicações (época de aplicação) e doses de inseticidas (Tabela1).

Em média, o tratamento com inseticida reduziu as infestações de cigarrinha, em comparação com as parcelas-testemunha, durante todo o período de ocorrência da praga, exceto na amostragem efetuada em 26/1/03 (Tabela 1). Entretanto, deve-se considerar que, nessa ocasião, houve diferenças entre os tratamentos inseticidas; nas parcelas tratadas sob infestação de 1,8 cigarrinhas $\mathrm{m}^{-1}$ (em 4/12/02) houve, em 26/1/03, infestações significativamente menores que aquelas tratadas sob infestação de 12,4 cigarrinhas. ${ }^{-1}$ (em 26/12/02), como discutido anteriormente (Tabela 1).

Embora os tratamentos inseticidas tenham reduzido as populações de cigarrinha em comparação à testemunha, na maior parte do período de ocorrência da praga, não interferiram nos valores de ATR, obtidos por ocasião da colheita (Tabela 2), sugerindo que, no presente ensaio, as populações de cigarrinha não foram altas o suficiente para reduzir o teor de açúcar nos colmos. No entanto, houve efeito dos tratamentos inseticidas sobre a produtividade de colmos e, conseqüentemente, de ATR (Tabela 2). Enquanto as parcelas testemunhas produziram 68,9 $\mathrm{t}$ ha ${ }^{-1}$ de colmos e $12,30 \mathrm{t} \mathrm{ha}^{-1}$ de ATR, as parcelas tratadas com thiamethoxam produziram em média $82,6 \mathrm{t} \mathrm{ha}^{-1}$ de colmos e $14,87 \mathrm{t} \mathrm{ha}^{-1}$ de ATR, valores significativamente maiores (Tabela 2). Esses dados são semelhantes aos verificados por DinARDO-MIRANDA et al. (2003), que também obtiveram incrementos significativos de produtividade de colmos e de ATR, em relação à testemunha, quando usaram thiamethoxam para controle de cigarrinha. 
Tabela 1. Infestação de M. fimbriolata (cigarrinhas. ${ }^{-1}$ de sulco) na variedade RB855536 de cana-de-açúcar em função dos tratamentos e datas de amostragem. Iracemápolis (SP), 2002/2003

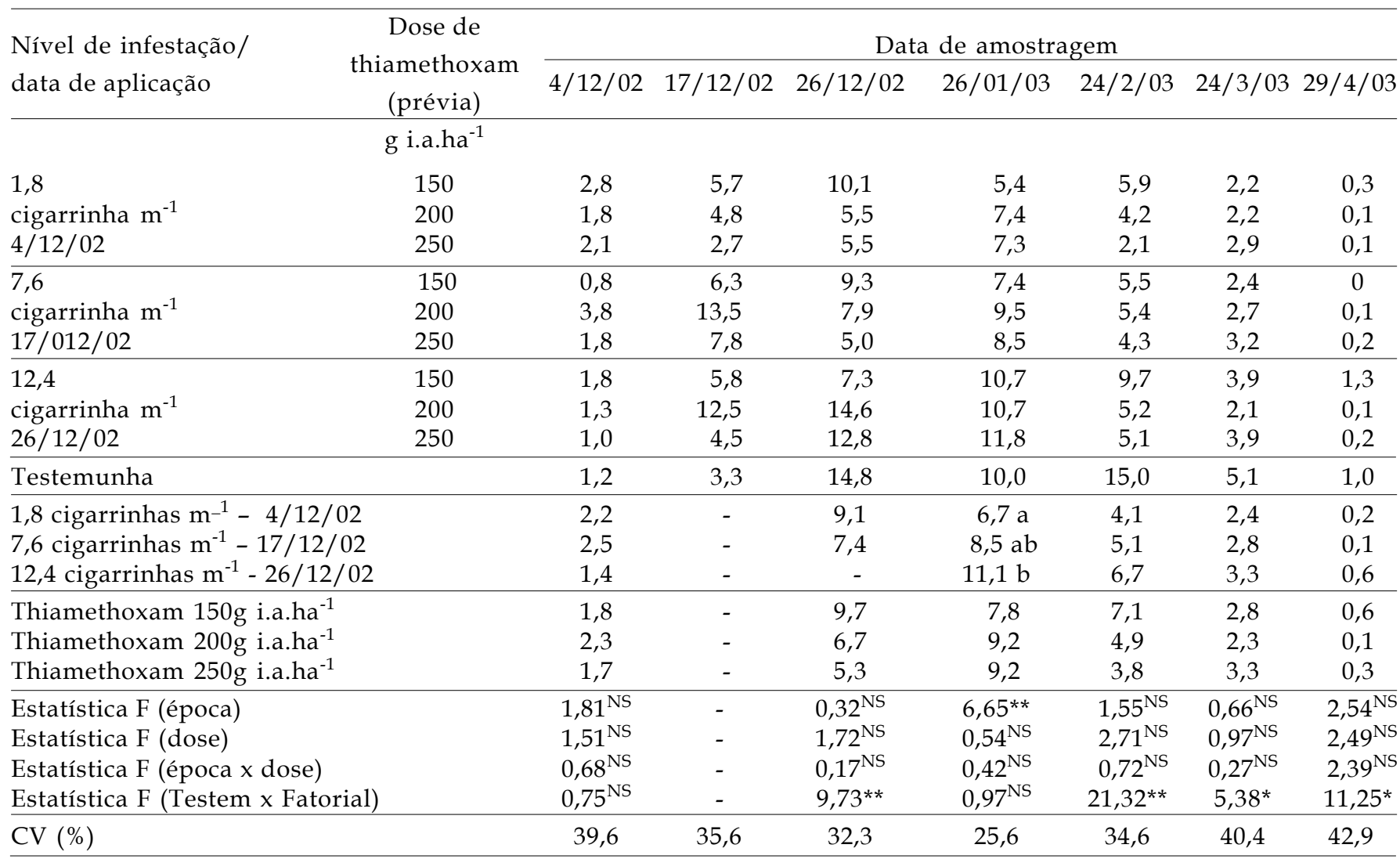

NS = não significativo; ${ }^{*} \mathrm{e}^{* *}=$ Significativo a $5 \%$ e a $1 \%$ de probabilidade respectivamente.

Para os dados de 17/12/02, a análise estatística foi feita considerando delineamento em blocos ao acaso.

Houve efeito da infestação quando foi aplicado o inseticida (infestação inicial) ou da época de aplicação sobre a produtividade (Tabela 2). O controle de cigarrinha feito quando as infestações estavam em 1,8 cigarrinhas $\mathrm{m}^{-1}$ (em 4/12/02) ou em 7,6 cigarrinhas $\mathrm{m}^{-}$ ${ }^{1}$ (em 17/12/02) resultou em produtividades de colmos e de ATR superiores às observadas quando o controle foi feito sob infestação de 12,4 cigarrinhas $\mathrm{m}^{-1}$. Esse resultado corrobora com observações de DINARDOMiRANDA et al. (2004) que, em experimentos nos quais foram feitas aplicações em várias épocas, obtiveram produtividades mais altas quanto mais rapidamente se fez o controle. Os autores concluíram que o controle de cigarrinha-das-raízes deveria ser feito o quanto antes, de preferência, no início do período de ocorrência da praga, quando ela ainda não teria causado danos irreparáveis à cultura. Ao se fazer o controle tardiamente, a cultura passaria por um longo período sob infestações elevadas da praga, sofrendo danos significativos, com redução de produtividade, mesmo após o controle.

Na média, não foram observadas diferenças entre as três doses de thiamethoxam quanto à produtividade de colmos e de ATR (Tabela 2).
A interação entre doses e infestação no período da aplicação (ou época de aplicação) do inseticida foi significativa a $25 \%$ de probabilidade. BANCROFT (1968) recomenda considerar preliminarmente como significativa a interação, mesmo quando é de $25 \%$, e prosseguir com as análises mais detalhadas. Assim, a análise do efeito de doses dentro de cada infestação na aplicação (ou época de aplicação) revelou que o efeito foi claramente significativo $(1 \%$ de significância) quando as aplicações foram feitas em $4 / 12 / 02$, sob infestação de 1,8 cigarrinhas $\mathrm{m}^{-1}$. Nessa ocasião, o tratamento com thiamethoxam a $250 \mathrm{~g}$ i.a. $\mathrm{ha}^{-1}$ resultou em produtividade de colmos e de ATR maior à do tratamento com 150 g i.a. ha ${ }^{-1}$ (Tabela 2). Dessa forma, ao utilizar a dose mais elevada de thiamethoxam, tem-se um residual mais longo e, portanto, mais adequado para proteger a cultura durante todo o período de ocorrência da praga. Outro fator importante foi que, na aplicação feita sob infestação inicial de 1,8 cigarrinhas $\mathrm{m}^{-1}$, em 4/12/02, thiamethoxam a $250 \mathrm{~g}$ i.a. ha ${ }^{-1}$ reduziu mais rapidamente as populações da praga do que quando utilizado em doses menores. 
Tabela 2. Açúcar total recuperável (ATR), produtividade de colmos e de ATR observados na colheita da variedade RB855536, em função dos tratamentos. Iracemápolis (SP), 2002/2003

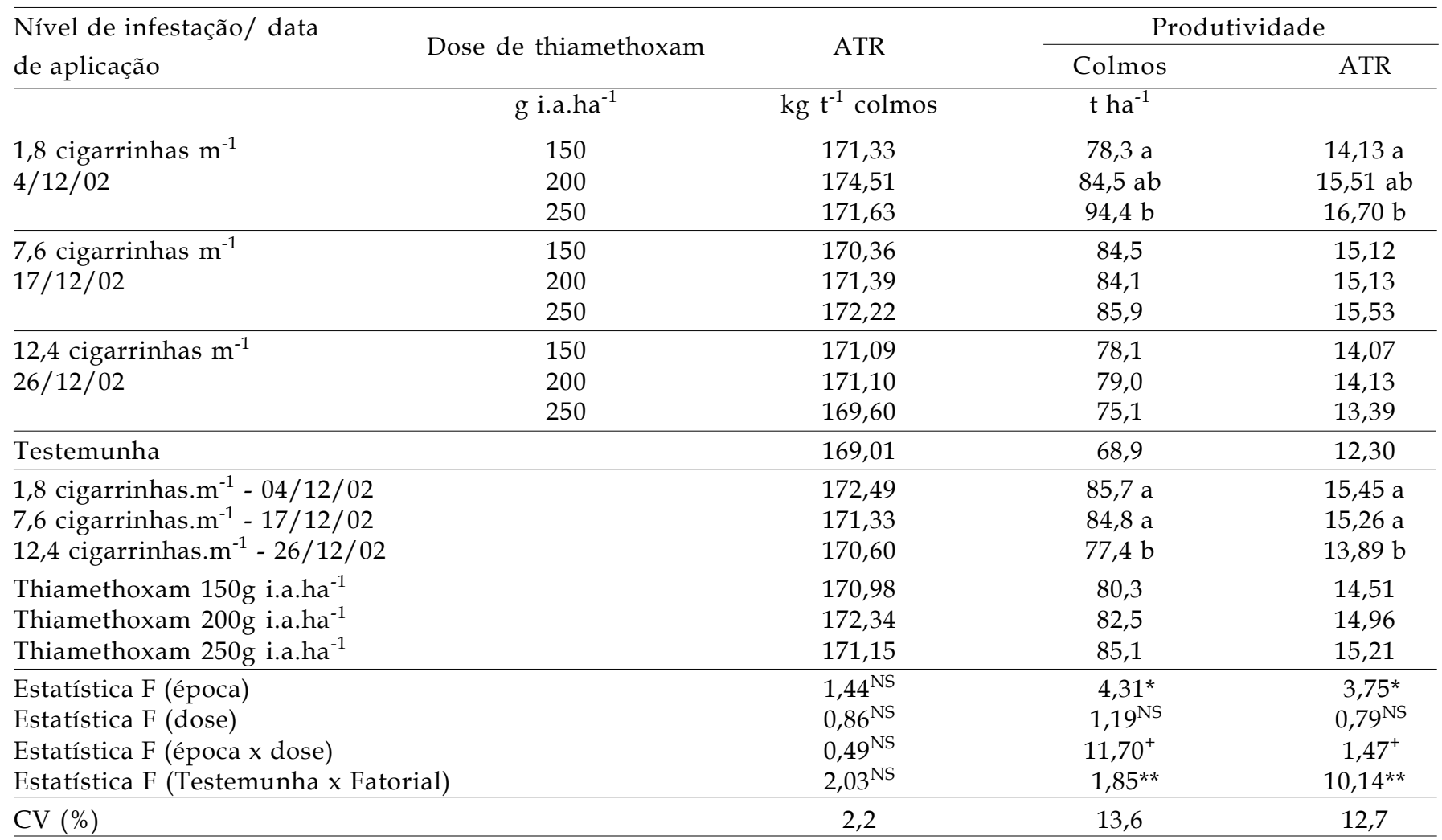

NS = não significativo $;+{ }^{*} e^{* *}=$ Significativo a $25 \%$, a $5 \%$ e a $1 \%$ de probabilidade respectivamente.

Do ponto de vista econômico, o controle de $M$. fimbriolata, quando as infestações foram de 1,8 cigarrinhas $\mathrm{m}^{-1}$, também se tornou mais viável do que quando efetuado sob infestação de 12,4 cigarrinhas $\mathrm{m}^{-1}$ (Tabela 3 ). O uso de thiamethoxam a $250 \mathrm{~g}$ i.a.ha ${ }^{-1}$, aplicado com infestação de 1,8 cigarrinhas. ${ }^{-1}$ resultou na maior receita líquida ( $\$ 1001,00$ por ha), contrapondo-se a $R \$ 35,00$ por ha obtidos ao se utilizar a dose de 250 g i.a.ha ${ }^{-1}$, sob infestação de 12,4 cigarrinhas $\mathrm{m}^{-1}$ (Tabela 3 ).

A análise econômica, considerando os dados médios das três doses empregadas e utilizadas comercialmente em campo, confirma que a maior receita líquida foi obtida com controle sob infestação de 1,8 cigarrinhas $\mathrm{m}^{-1}$ (Tabela 4). Por outro lado, houve sensível decréscimo na receita líquida ao reduzir a dose do inseticida (Tabela 5), revelando que, apesar de se constituir em tratamento mais caro, se comparado com a dose de 150 g i.a. ha ${ }^{-}$ 1 , thiamethoxam a 250 g i.a.ha ${ }^{-1}$ proporcionou maiores vantagens econômicas, em decorrência do melhor controle da praga.
Com base nos valores médios das três doses de aplicação de thiamethoxam e as respectivas MCAIs (Tabela 4), elaborou-se a curva de regressão da MCAI em vista da infestação de cigarrinha-dasraízes, à época do controle. Para tanto, a infestação máxima atingida nas parcelas testemunhas (15 cigarrinhas $\mathrm{m}^{-1}$ ) foi relacionada à MCAI da testemunha ( $\mathrm{R} \$ 3.091,00$ por ha), obtendo-se a curva $\mathrm{Y}=4194-62,7 \mathrm{X}$, em que: $\mathrm{Y}$ representa a MCAI (R\$ $\mathrm{ha}^{-1}$ ) e $\mathrm{X}$ a infestação da cigarrinha-das-raízes (cigarrinhas $\mathrm{m}^{-1}$ ), com r ${ }^{2}$ igual a 0,84 (Figura 1 ). Os valores de $\mathrm{F}$ e $\mathrm{p}$ resultantes da análise estatística foram, respectivamente, 10,3141 e 0,0848 , revelando que a significância é de aproximadamente $9 \%$, que pode ser considerada satisfatória para trabalhos entomológicos. Dessa forma, a MCAI na ausência da praga $(X=0)$ seria de $R \$ 4.194,00$ por hectare e, portanto, considerando os dados médios, os níveis de dano econômico da praga seriam de 4,8 , 3,9 e 3,1 cigarrinhas $\mathrm{m}^{-1}$, ao utilizar thiamethoxam nas doses de 250,200 e 150 g i.a. ha ${ }^{-1}$, uma vez que os custos de controle (inseticida + aplicação) seriam, respectivamente, $\mathrm{R} \$ 300,00, \mathrm{R} \$ 246,00$ e $\mathrm{R} \$ 192,00$ por hectare. 
Tabela 3. Margem de contribuição agroindustrial (MCAI, R\$.ha ${ }^{-1}$ ) em função dos tratamentos, variação da MCAI dos tratamentos em relação à testemunha $\left(B, R \$ \cdot h a^{-1}\right)$, custo do tratamento inseticida $\left(C=\right.$ produto + aplicação, $R$ \$.ha $\left.{ }^{-1}\right)$ e receita líquida obtida com os tratamentos (B - C, R\$.ha $\left.{ }^{-1}\right)$. Iracemápolis (SP), 2002/2003

\begin{tabular}{|c|c|c|c|c|c|}
\hline Tratamento & $\begin{array}{l}\text { Nível de Infestação } \\
\text { (data da aplicação) }\end{array}$ & MCAI & $\begin{array}{c}\text { Variação } \\
\text { da MCAI (B) }\end{array}$ & $\begin{array}{l}\text { Custo do tratamento } \\
\text { (C) }\end{array}$ & $\begin{array}{c}\text { Receita líquida } \\
\text { (B-C) }\end{array}$ \\
\hline & & & $\mathrm{R} \$ \mathrm{ha}^{-1}$ & & \\
\hline Testemunha & - & 3091,00 & - & - & - \\
\hline Thiamethoxam $150 \mathrm{~g}$ i.a.ha ${ }^{-1}$ & 1,8 & 3549,00 & 458,00 & 192,00 & 266,00 \\
\hline Thiamethoxam 200g i.a.ha ${ }^{-1}$ & cigarrinha $\mathrm{m}^{-1}$ & 3985,00 & 894,00 & 246,00 & 648,00 \\
\hline Thiamethoxam $250 \mathrm{~g}$ i.a.ha ${ }^{-1}$ & $(4 / 12 / 02)$ & 4392,00 & 1301,00 & 300,00 & 1001,00 \\
\hline Thiamethoxam 150g i.a.ha-1 & 7,6 & 3831,00 & 740,00 & 192,00 & 548,00 \\
\hline Thiamethoxam 200g i.a.ha ${ }^{-1}$ & cigarrinha $\mathrm{m}^{-1}$ & 3841,00 & 750,00 & 246,00 & 504,00 \\
\hline Thiamethoxam $250 \mathrm{~g}$ i.a.ha ${ }^{-1}$ & $(17 / 12 / 02)$ & 3965,00 & 874,00 & 300,00 & 574,00 \\
\hline Thiamethoxam 150g i.a.ha-1 & 12,4 & 3569,00 & 478,00 & 192,00 & 286,00 \\
\hline Thiamethoxam 200g i.a.ha ${ }^{-1}$ & cigarrinha $\mathrm{m}^{-1}$ & 3607,00 & 516,00 & 246,00 & 270,00 \\
\hline Thiamethoxam 250g i.a.ha ${ }^{-1}$ & $(26 / 12 / 02)$ & 3426,00 & 335,00 & 300,00 & 35,00 \\
\hline
\end{tabular}

Tabela 4. Margem de contribuição agroindustrial (MCAI) em função da infestação por ocasião da aplicação do inseticida (média das três doses de inseticida), variação da MCAI dos tratamentos em relação à testemunha (B), custo médio do tratamento inseticida $\left(C=\right.$ produto + aplicação, $\left.R \$ \cdot h a^{-1}\right)$ e receita líquida obtida com os tratamentos $(B-C)$. Iracemápolis (SP), 2002/2003

\begin{tabular}{|c|c|c|c|c|}
\hline Tratamento & MCAI & $\begin{array}{c}\text { Variação da MCAI } \\
\text { (B) }\end{array}$ & $\begin{array}{l}\text { Custo do tratamento } \\
\text { (C) }\end{array}$ & $\begin{array}{c}\text { Receita líquida } \\
\text { (B-C) }\end{array}$ \\
\hline & \multicolumn{4}{|c|}{$\mathrm{R} \$ \mathrm{ha}^{-1}$} \\
\hline Testemunha & 3091,00 & - & - & - \\
\hline Aplicação a 1,8 cigarrinhas $\mathrm{m}^{-1}$ & 3970,00 & 879,00 & 246,00 & 633,00 \\
\hline Aplicação a 7,6 cigarrinhas $\mathrm{m}^{-1}$ & 3875,00 & 784,00 & 246,00 & 538,00 \\
\hline Aplicação a 12,4 cigarrinhas $\mathrm{m}^{-1}$ & 3534,00 & 443,00 & 246,00 & 197,00 \\
\hline
\end{tabular}

Tabela 5. Margem de contribuição agroindustrial (MCAI) em função da dose do inseticida (média das três épocas de aplicação), variação da MCAI dos tratamentos em relação à testemunha (B), custo do tratamento inseticida $(\mathrm{C}=$ produto + aplicação) e receita líquida obtida com os tratamentos (B - C). Iracemápolis (SP), 2002/2003

\begin{tabular}{|c|c|c|c|c|}
\hline Tratamento & MCAI & $\begin{array}{c}\text { Variação da MCAI } \\
\text { (B) }\end{array}$ & $\begin{array}{l}\text { Custo do tratamento } \\
\text { (C) }\end{array}$ & $\begin{array}{c}\text { Receita líquida } \\
\text { (B-C) }\end{array}$ \\
\hline & & $-\mathrm{r}$ & -1 & \\
\hline Testemunha & 3091,00 & - & - & - \\
\hline Thiamethoxam $150 \mathrm{~g}$ i.a.ha ${ }^{-1}$ & 3649,00 & 558,00 & 192,00 & 366,00 \\
\hline Thiamethoxam $200 \mathrm{~g}$ i.a.ha ${ }^{-1}$ & 3806,00 & 715,00 & 246,00 & 469,00 \\
\hline Thiamethoxam $250 \mathrm{~g}$ i.a.ha ${ }^{-1}$ & 3923,00 & 832,00 & 300,00 & 532,00 \\
\hline
\end{tabular}


Optando-se por utilizar somente os dados relativos a thiamethoxam a 250 g i.a.ha ${ }^{-1}$ (Tabela 3), por ter proporcionado o melhor controle da praga, a curva que mais bem representa a MCAI (Y, R\$ por ha) em função da infestação da praga $\left(X\right.$, cigarrinhas $\mathrm{m}^{-}$ $\left.{ }^{1}\right)$ é dada por $\mathrm{Y}=4623-98,4 \mathrm{X}, \mathrm{com} \mathrm{r}^{2}$ igual a 0,99 (Figura 1); os valores de $\mathrm{F}$ e $\mathrm{p}$ verificados na análise estatística foram, respectivamente, de 133,71 e 0,0071 , com significância de $1 \%$. Assim, pode-se inferir que a MCAI na ausência da praga $(X=0)$ seria de $\mathrm{R} \$ 4.623,00$ por hectare e, ao se utilizar thiamethoxam na dose de $250 \mathrm{~g}$ i.a. $\mathrm{ha}^{-1}$, o NDE seria de aproximadamente 3 cigarrinhas $\mathrm{m}^{-1}$.

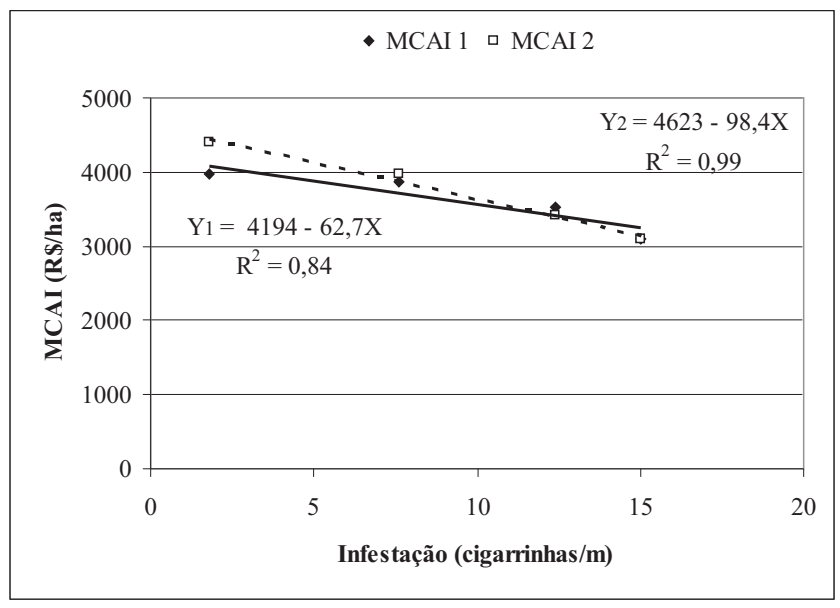

Figura 1. Margem de contribuição agroindustrial $(Y=$ MCAI, R\$.ha ${ }^{-1}$ ) da variedade RB855536 de cana-deaçúcar em função das infestações de cigarrinha-das-raízes por ocasião do tratamento químico $\left(X\right.$, cigarrinhas. $\left.\mathrm{m}^{-1}\right)$, sendo $Y_{1}$ calculada utilizando os dados médios das três doses de thiamethoxam e $\mathrm{Y}_{2}$, os dados do tratamento com thiamethoxam a $250 \mathrm{~g}$ i.a. ha ${ }^{-1}$.

Embora ocorressem alterações nos preços dos produtos finais e nos custos de produção nos últimos anos, os valores ora obtidos se aproximam bastante dos observados por Dinardo-Miranda (2003), que, analisando diversos dados experimentais e de áreas comerciais, sugeriu que o NDE para canaviais colhidos em fim de safra, tal como no presente ensaio, estaria ao redor de 4 cigarrinhas $\mathrm{m}^{-1}$.

Por outro lado, os valores estimados no presente trabalho contradizem MACEDO e MACEDO (2004), que afirmaram haver indicações de que o nível de dano econômico da cigarrinha estaria entre 8 e 10 ninfas $\mathrm{m}^{-1}$. Os autores citados, entretanto, não forneceram outros detalhes importantes sobre o assunto, tal como o estágio de desenvolvimento do canavial ao qual tal nível seria referente.
Obviamente, além dos preços dos produtos finais e dos custos de produção, muitos fatores interferem na definição do nível de dano econômico, como discutido por Pedigo et al. (1986), entre os quais idade da planta ao sofrer a injúria, intensidade da injúria, variedade cultivada e condições ambientais. Em cana-de-açúcar, na qual se tem soqueiras colhidas de abril a novembro, inúmeras variedades plantadas e condições ambientais de cultivo das mais diversas, a definição do NDE da cigarrinha-das-raízes é tarefa bastante complexa. No entanto, a necessidade da definição do NDE é premente, dada a importância da praga nas condições paulistas. $\mathrm{O}$ valor estimado neste trabalho, entre 3 e 5 cigarrinhas $\mathrm{m}^{-1}$, deve atender os casos de variedades suscetíveis, colhidas em fim de safra, tal como neste experimento. Para variedades colhidas em começo de safra, o NDE é maior do que o aqui estabelecido, uma vez que a cultura tem condições de suportar populações maiores da praga sem ocorrer danos, por estar mais desenvolvida por ocasião da ocorrência da cigarrinha (DiNARDoMiranda et al 1999, 2001a; DinARDo-Miranda 2003).

\section{CONCLUSÃO}

O nível de dano econômico da cigarrinha-dasraízes, M. fimbriolata, para a cana-de-açúcar colhida em fim de safra (novembro) é de 3 a 5 cigarrinhas $\mathrm{m}^{-1}$.

\section{AGRADECIMENTOS}

Os autores agradecem ao Professor Dr. Dilermando Perecin, da UNESP de Jaboticabal (SP), pela ajuda nas análises estatísticas.

\section{REFERÊNCIAS}

BANCROFT, T.A. Topics in intermediate statistical methods. Ames, Iowa: The Iowa State University Press, 1968. 129p.

DINARDO-MIRANDA, L.L. Cigarrinha-das-raízes em canade-açúcar. Campinas: Instituto Agronômico, 2003. 72p.

DINARDO-MIRANDA, L.L.; COELHO, A.L.; FERREIRA, J.M.G. Influência da época de aplicação de inseticidas no controle de Mahanarva fimbriolata (Stål) (Hemiptera: Cercopidae), na qualidade e na produtividade da cana-de-açúcar. Neotropical Entomology, Londrina, v.33, n.1, p. 91-98, 2004.

DINARDO-MIRANDA, L.L.; FERREIRA, J.M.G.; CARVALHO, P.A.M. Influência da época de colheita e do genótipo da canade-açúcar sobre a infestação de Mahanarva fimbriolata (Stål) (Hemiptera: Cercopidae). Neotropical Entomology, Londrina, v.30, n.1, p.145-149, 2001a. 
DINARDO-MIRANDA, L.L.; FERREIRA, J.M.G.; CARVALHO, P.A.M. Influência das cigarrinhas das raízes, Mahanarva fimbriolata, sobre a qualidade tecnológica da cana-de-açúcar. STAB - Açúcar, Álcool e Subprodutos, Piracicaba, v.19, n.2, p.34-35. 2000.

DINARDO-MIRANDA, L.L.; FIGUEIREDO, P.; LANDELL, M.G.A.; FERREIRA, J.M.G.; CARVALHO, P.A.M. Danos causados pelas cigarrinhas-das-raízes (Mahanarva fimbriolata) a diversos genótipos de cana-de-açúcar. STAB - Açúcar, Álcool e Subprodutos, Piracicaba, v.17, n.5, p.48-52, 1999.

DINARDO-MIRANDA, L.L.; MOSSIM, G.C.; DURIGAN, A.M.P.R.; BARBOSA, V. Controle químico de cigarrinha das raízes em cana-de-açúcar. STAB - Açúcar, Álcool e Subprodutos, Piracicaba, v.19, n. 4, p.20-23, 2001b.

DINARDO-MIRANDA, L.L.; NAKAMURA, G; ZOTARELLI, L.; BRAZ, B.A.; EUZÉBIO, O. Viabilidade técnica e econômica de Actara 250WG, aplicado em diversas doses, no controle de cigarrinha-das-raízes. STAB - Açúcar, Álcool e Subprodutos, Piracicaba, v.22, n.1, p. 39-43, 2003.
FERNANDEZ, A. C. Cálculos na agroindústria da cana-deaçúcar. 2.ed. Piracicaba: STAB, 2003. 240p.

GONÇALVES, T.D.; MUTTON, M.A.; PERECIN, D.; CAMPANHÃO, J.M.; MUTTON, M.J.R. Qualidade da matériaprima em função de diferentes níveis de danos promovidos pela cigarrinha-das-raízes. STAB - Açúcar, Álcool e Subprodutos, Piracicaba, v.22, n.2, p.29-33, 2003.

MACEDO, N.; BOTELHO, P.S.M.; CAMPOS, M.B.S. Controle químico da cigarrinha-da-raiz em cana-de-açúcar e impacto sobre a população de artrópodes. STAB - Açúcar, Álcool e Subprodutos, Piracicaba, v.21, n.4, p. 30-33, 2003.

MACEDO, N; MACEDO, D. As pragas de maior incidência nos canaviais e seus controles. Visão Agrícola, Piracicaba, v.1, n.1, p.38-46, 2004.

PEDIGO, L.P.; HUTCHINS, S.H.; HIGLEY, L.G. 1986. Economic injury levels in theory and practice. Annual Review of Entomology, v.31, p.341-368, 1986. 